\title{
COVID-19 in persons affected by Hansen's disease in Brazil
}

Patrícia D. Deps (MD PhD), ${ }^{1,2 *}$ Taynah A. R. Repsold (MD), ${ }^{2}$ Claudio G. Salgado (MD $\mathrm{PhD}){ }^{3}$ Raquel de Carvalho Bouth (BSc), ${ }^{3}$ Selma Regina Penha Silva Cerqueira (BSc), ${ }^{4}$ Marisa Simon Brezinscki (MD), ${ }^{5}$ Rebeca Ruppert Galarda Baptista Peixoto (MD), ${ }^{5}$ Jaison Antonio Barreto (MD PhD), ${ }^{6}$ Andrea M. A. Fonseca (MD), ${ }^{7}$ Marlene L. S. Peixoto (BSc), ${ }^{8}$ Seyna Ueno R. Mendes (MD), ${ }^{9}$ Rafael Pereira Rabelo Mendes (MD), ${ }^{9}$ Pedro Paulo dos Santos Oliveira (BSc), ${ }^{9}$ Ciro Martins Gomes (MD PhD) ${ }^{4}$

1. Department of Social Medicine, Universidade Federal do Espírito Santo, Vitória, Espírito Santo, Brazil

2. Postgraduate Programme in Infectious Diseases, Universidade Federal do Espírito Santo, Vitória, Espírito Santo, Brazil

3. Laboratório de Dermato-Imunologia, Universidade Federal do Pará, Marituba, Pará, Brazil

4. Núcleo de Medicina Tropical, Universidade de Brasília, Brazil

5. Hospital da Santa Casa de Misericórdia de Vitória, Vitória, Espírito Santo, Brazil

6. Instituto Lauro de Souza Lima, Bauru, São Paulo, Brazil

7. Serviço de Infectologia de Petrolina, Petrolina, Pernambuco, Brazil

8. Secretária Executiva de Vigilância em Saúde, Secretaria Municipal de Saúde de Petrolina, Pernambuco, Brazil

9. Serviço de Referência em Hansenologia, Secretaria Municipal de Saúde de Palmas, Tocantins, Brazil

* Corresponding Author: Professor Patrícia Deps, Departamento de Medicina Social, Centro de Ciências da Saúde, Avenida Marechal Campos, 1468. Maruípe, Vitória-ES, Brazil. CEP 29047-105; email patricia.deps@ufes.br

Sources of support: This study received no specific funding

Conflicts of interest: None 


\begin{abstract}
Background: Hansen's disease (HD) is endemic in Brazil, a country with the third highest number of COVID-19 cases in the world and the second highest number of COVID-19 deaths. COVID-19 in persons affected by HD has not been described at population level in this country.
\end{abstract}

Methods: We collated numbers of COVID-19 cases and deaths among patients who were receiving routine treatment for HD at six centres across Brazil (Belém, Bauru, Brasília, Vitória, Petrolina, Palmas) between $1^{\text {st }}$ March and $10^{\text {th }}$ December 2020.

Results: Of 1,333 HD patients receiving treatment, 70 (5.2\%) reported having had COVID-19. Almost all patients $(97 \%(1,296 / 1,333))$ including all but one of the COVID-19 cases were receiving MDT comprising rifampicin (600mg once per month), dapsone (100mg daily), and clofazimine (50 mg daily plus $300 \mathrm{mg}$ once per month). Four patients died, including a patient in their 30's on MDT who had a severe type 2 HD reaction (erythema nodosum leprosum) and who was taking clofazimine 100mg daily.

Conclusions: We cannot determine from these preliminary data whether persons affected by Hansen's disease have a higher or lower risk of COVID-19 and related mortality compared with the general population. We will continue to monitor the effects of COVID-19 in persons affected by and treated for HD and extend this to monitor SARS-CoV-2 vaccine effectiveness in this group of patients. 


\section{Introduction}

Hansen's disease remains endemic in Brazil, with 30,000 new cases diagnosed each year [1]. Brazil is also one of the countries most severely impacted by the COVID-19 pandemic, reporting 6 million cases and 170,000 deaths to the end of November 2020 [2]. As a first step to investigating occurrence and outcomes of COVID-19 in persons affected by Hansen's disease, we analysed data from six centres in Brazil treating patients with Hansen's disease from $1^{\text {st }}$ March to $10^{\text {th }}$ December 2020. Routine multidrug therapy for HD includes clofazimine, which was demonstrated to have SARS-CoV-2 antiviral activity in an animal model. This has led to the suggestion that clofazimine might have effects against COVID-19 in humans. We review the history of clofazimine as a treatment for $\mathrm{HD}$ and discuss whether it merits investigation as a treatment for COVID-19.

\section{Methods}

Six HD treatment centres were recruited to the study, one each in the municipalities of Belém (state of Pará), Bauru (São Paulo), Brasília (Goias), Vitória (Espírito Santo), Petrolina (Pernambuco), and Palmas (Tocantins). Numbers of patients treated for HD at each centre were collated together with reported diagnoses of COVID-19 and deaths attributed to COVID-19 (from clinic records). Patients attending one centre (Brasília) were routinely tested (by PCR) for COVID-19. Background cumulative incidence of COVID-19 in each municipality was obtained from publicly available national surveillance data (https://covid.saude.gov.br/). Ethical approval was obtained from the research ethics committee (Comitê de Ética em Pesquisa, CEP) of the Universidade Federal do Espírito Santo (UFES), certificate no. 40347520.5.0000.5060. 


\section{Results}

Of 1,333 patients attending the six clinics between March $1^{\text {st }}$ and December $10^{\text {th }}, 2020$, $70(5.2 \%)$ reported having had COVID-19 (Table 1). Most of the patients (97\% $(1,296 / 1,333))$ including all but one of the COVID-19 cases were receiving MDT comprising rifampicin (600mg once per month), dapsone (100mg daily), and clofazimine (50 mg daily plus $300 \mathrm{mg}$ once per month). Four patients died, including a patient in their 30's on MDT who had a severe type 2 Hansen's disease reaction (erythema nodosum leprosum, ENL) and who was taking clofazimine 100mg daily.

Table 1. Persons affected by Hansen's disease and COVID-19 diagnoses at four centres in Brazil, from March $1^{\text {st }}$ to December $10^{\text {th }}, 2020$

\begin{tabular}{|lrrrr|}
\hline Centre & $\begin{array}{r}\text { Persons with } \\
\text { Hansen's disease }\end{array}$ & $\begin{array}{r}\text { Persons diagnosed } \\
\text { with COVID-19 }\end{array}$ & $\begin{array}{r}\text { COVID-19 } \\
\text { deaths }\end{array}$ & $\begin{array}{r}\text { Background } \\
\text { COVID-19 } \\
\text { cumulative } \\
\text { incidence }\end{array}$ \\
Belém & 83 & $6(7.2 \%)$ & 0 & $3.5 \%$ \\
Bauru & 100 & $1(1.0 \%)$ & 0 & $4.4 \%$ \\
Brasília & 98 & $13(13.3 \%)^{\dagger}$ & 0 & $7.8 \%$ \\
Vitória & 66 & $1(1.5 \%)$ & 1 & $6.9 \%$ \\
Petrolina & 463 & $14(3.0 \%)$ & 1 & $2.7 \%$ \\
Palmas & 523 & $35(6.7 \%)$ & 2 & $6.6 \%$ \\
\multicolumn{1}{c}{ Total } & 1333 & $70(5.2 \%)$ & 4 & $6.1 \%$ \\
\hline
\end{tabular}

${ }^{\dagger}$ Hansen's disease patients at this centre were tested routinely (PCR) for COVID-19

National surveillance data to December $10^{\text {th }}, 2020$, from https://covid.saude.gov.br/ 


\section{Discussion}

This is the first population-level report of cases of COVID-19 among persons affected by HD. Whilst the cumulative incidence of COVID-19 in patients receiving treatment for HD appears similar to the background cumulative incidence of COVID-19 in each municipality, we cannot determine from these preliminary data whether persons affected by Hansen's disease have a higher or lower risk of COVID-19 and associated mortality than the general population. This comparison would require adjustment for differences in age, sex and other factors. The relatively high rate of COVID-19 among HD patients in Brasília reflects routine testing for COVID-19 at this centre, a practice that other centres might consider adopting subject to availability of resources. We will continue to monitor the effects of COVID-19 in persons affected by and treated for HD and we plan to extend this to monitor SARS-CoV-2 vaccine effectiveness in this group of patients.

Both COVID-19 and reactional states in Hansen's disease can present a severe cytokine storm, with markedly higher levels of pro-inflammatory cytokines including interferons, tumour necrosis factors, interleukins, and chemokines $[3,4]$. In relation to the patient in our preliminary data who had ENL and who died from COVID-19, both conditions share immunological aspects related to generalized neutrophil infiltration: in SARSCoV-2 infection, extensive neutrophil infiltration in pulmonary capillaries [5]; in ENL, extensive dermal neutrophil infiltration [6]. COVID-19 neutrophils may trigger ENL or increase its severity, or vice-versa. Systemic corticosteroids are important drugs for the treatment of COVID-19 and Hansen's disease reactions. Prolonged, high-dose treatment with prednisolone (for 12-14 weeks) causing immunosuppression would increase risks associated with SARS-CoV-2 infection [7]. 
A recent large-scale drug repurposing study identified clofazimine (N,5-bis(4chlorophenyl)-3-(1-methylethylimino)-5H-phenazin-2-amine) as a potential SARS-

CoV-2 antiviral agent [8]. In a follow-up study, clofazimine in vitro and in hamsters demonstrated inhibitory activity against SARS-CoV-2 replication and reduced expression of IL- 6 , TNF- $\alpha$, and CCR4 that suggested potential to reduce the cytokine storm that can occur in COVID-19 [9]. The possible effects of clofazimine on severity of SARS-CoV-2 infection have not been studied in people, but a phase II clinical trial was registered (Hong Kong, China) in July 2020 [NCT04465695].

Other than off-label use for dermatological conditions and atypical mycobacterial infections [10], clofazimine is used routinely only for the treatment of Hansen's disease as a component of the WHO multidrug therapy (MDT) regimen comprising dapsone, clofazimine and rifampicin [11]. Clofazimine is a riminophenazine dye with bacteriostatic and anti-inflammatory actions, the mechanisms of which are largely unknown but possibly including direct activity affecting bacterial DNA [10]. Clofazimine is well tolerated in the current dosage for Hansen's disease (50mg daily plus 300mg monthly), with mild side effects including dryness and hyperpigmentation of the skin [12], ocular conjunctiva and organic fluids [13]. At doses above 100mg daily, clofazimine can cause gastrointestinal symptoms; these can manifest as small bowel syndrome, a more serious side effect characterized by persistent diarrhoea, weight loss and abdominal pain [13-15]. The skin discoloration due to medium to longterm use of clofazimine can cause distress and has been associated with the stigmatisation of persons affected by Hansen's disease [16].

According to Yuan et al., the dose of clofazimine which demonstrated efficacy against SARS-CoV-2 in hamsters was $25 \mathrm{mg} / \mathrm{kg}$, corresponding to $200 \mathrm{mg} /$ day in humans [9]. 
Reports from the 1970's described use of clofazimine at 100, 200 and $300 \mathrm{mg} /$ day for more than two months with few serious side effects $[15,17,18]$. Opromolla et al. (1972) reported excellent tolerance and good therapeutic results using $300 \mathrm{mg} / \mathrm{day}$, and clofazimine was considered to have potent anti-inflammatory activity that translated into neutralisation of or prophylaxis against Hansen's disease reactions [15]. Doses of $300 \mathrm{mg} /$ day are still included in national guidelines for the control of reactional states as an alternative to systemic corticosteroids in immunosuppressive doses [19].

Silva et al. (1972) commented that clofazimine is easily absorbed through the oral route, does not reach high concentrations in the blood because it is quickly captured by the cells of the endothelial reticulum system, and is deposited preferentially in the lungs, liver and skin; it is eliminated in urine, to which it lends a reddish colour, and by the sebaceous glands; dosages in excess of $400 \mathrm{mg}$ /day were not recommended because of gastrointestinal side effects [18]. Clofazimine appears not to accumulate in blood or tissues, therefore in cases of treatment interruption a therapeutic effect is not guaranteed [20]. Conversely, recent pharmacokinetic studies in mouse models point to a possible cumulative effect of clofazimine after 2 weeks to 2 months of regular use and a possible increase in its half-life [21].

For as long as COVID-19 has few prophylactic drugs, and whilst awaiting distribution of vaccines which may take time to reach populations in remote and less well-resourced areas, it has been suggested that clofazimine merits further investigation in relation to possible protective effects against COVID-19. Considering the acute evolution time and high case fatality of COVID-19, side effects from higher doses or prolonged treatment would not be a limitation if clofazimine proved to be effective in suppressing the virus. 
However, we have some doubts that data from this patient group can provide evidence regarding the potential effectiveness of clofazimine against COVID-19:

1. In most centres, occurrence of COVID-19 is reported by patients or their family members to the health care professionals at monthly consultations

2. Many Hansen's disease patients have had reduced access to health care services during the COVID-19 pandemic

3. Shortages of MDT mean that treatment is not available in many centres or patients have stopped taking MDT during the COVID-19 pandemic

4. Effects of clofazimine can be investigated by comparing Hansen's disease patients who are receiving or not receiving clofazimine, but this restricts the generalizability of findings to the general population and results might be confounded by indication

5. Effects of clofazimine can be investigated by comparing Hansen's disease patients who are receiving clofazimine with the general population, but any results will be heavily confounded by pathophysiological effects of Hansen's disease and differences between patients and the general population and the effect of clofazimine cannot be isolated from the other components of MDT

6. The dosage of clofazimine in MDT for Hansen's disease (50 mg/day) is far below the equivalent dose (200 mg/day) extrapolated from Yuan et al. [9]

Although clofazimine has few side effects and is rarely replaced, antibiotics (including minocycline, ofloxacin, doxycycline, clarithromycin, moxifloxacin) are indicated to replace MDT components in cases where side effects are sufficiently serious [14, 22], or in cases of treatment failure and resistance. Corticosteroids and thalidomide are recommended to control Hansen's disease reactions, and vitamin D, bisphosphonates, 
and aspirin to reduce treatment-related damage [23]. Analgesics, nonsteroidal antiinflammatories, antibiotics, metformin, proton-pump inhibitors, amitriptyline, gabapentin, simvastatin are also used during treatment of Hansen's disease [23]. This polypharmacy would further confound any estimated effects of clofazimine.

One clinical trial of oral clofazimine for COVID-19 has been registered, using oral clofazimine $100 \mathrm{mg}$ twice daily on day 1 , then $100 \mathrm{mg}$ daily for 2 days, compared with the same regimen plus a 3-day course of interferon $\beta$-1b [NCT04465695]. To investigate the effectiveness of clofazimine against severity of SARS-CoV-2 infection, we think that a higher dose of clofazimine can be given safely for a longer period. We would propose a clinical trial including oral clofazimine $200 \mathrm{mg} / \mathrm{day}$ for around two weeks. The experience of Brazilian physicians in routine use of clofazimine, including in high doses for HD reactions, and the currently high incidence of COVID-19 would make Brazil an ideal setting for such a study. In the meantime, we will continue to monitor the effects of COVID-19 in persons affected by and treated for Hansen's disease, and extend this to monitor SARS-CoV-2 vaccine efficacy in this group of patients. 


\section{References}

1. WHO. Weekly epidemiological record Nos 35/36. Geneva: WHO, 2019 30/08/2019.

2. COVID-19 no Brasil Brasília: Ministério da Saúde,. 2020 [05/12/2020]. Available from: https://susanalitico.saude.gov.br/extensions/covid-19 html/covid19_html.html.

3. Zhang Y, Zhong Y, Pan L, Dong J. Treat 2019 novel coronavirus (COVID-19) with IL-6 inhibitor: Are we already that far? Drug discoveries \& therapeutics. 2020;14(2):100-2. Epub 2020/05/08. doi: 10.5582/ddt.2020.03006. PubMed PMID: 32378647 .

4. Antunes DE, Goulart IMB, Goulart LR. Will cases of leprosy reaction increase with COVID-19 infection? PLoS neglected tropical diseases. 2020;14(7):e0008460. Epub 2020/07/18. doi: 10.1371/journal.pntd.0008460. PubMed PMID: 32678816; PubMed Central PMCID: PMCPMC7367444.

5. Barnes BJ, Adrover JM, Baxter-Stoltzfus A, Borczuk A, Cools-Lartigue J, Crawford JM, et al. Targeting potential drivers of COVID-19: Neutrophil extracellular traps. The Journal of experimental medicine. 2020;217(6). Epub 2020/04/18. doi: 10.1084/jem.20200652. PubMed PMID: 32302401.

6. Oliveira RB, Moraes MO, Oliveira EB, Sarno EN, Nery JA, Sampaio EP. Neutrophils isolated from leprosy patients release TNF-alpha and exhibit accelerated apoptosis in vitro. Journal of leukocyte biology. 1999;65(3):364-71. Epub 1999/03/18. doi: 10.1002/jlb.65.3.364. PubMed PMID: 10080541.

7. Wang C, Rademaker M, Baker C, Foley P. COVID-19 and the use of immunomodulatory and biologic agents for severe cutaneous disease: An Australian/New Zealand consensus statement. The Australasian journal of dermatology. 2020;61(3):210-6. Epub 2020/04/08. doi: 10.1111/ajd.13313. PubMed PMID: 32255510; PubMed Central PMCID: PMCPMC7262046.

8. Riva L, Yuan S, Yin X, Martin-Sancho L, Matsunaga N, Pache L, et al. Discovery of SARS-CoV-2 antiviral drugs through large-scale compound repurposing. Nature. 2020;586(7827):113-9. Epub 2020/07/25. doi: 10.1038/s41586-020-2577-1. PubMed PMID: 32707573; PubMed Central PMCID: PMCPMC7603405.

9. Yuan S, Yin X, Meng X, Chan J, Ye ZW, Riva L, et al. Clofazimine is a broadspectrum coronavirus inhibitor that antagonizes SARS-CoV-2 replication in primary human cell culture and hamsters. Res Sq. 2020. Epub 2020/10/15. doi: 10.21203/rs.3.rs86169/v1. PubMed PMID: 33052331; PubMed Central PMCID: PMCPMC7553155.

10. Arbiser JL, Moschella SL. Clofazimine: a review of its medical uses and mechanisms of action. Journal of the American Academy of Dermatology. 1995;32(2 Pt 1):241-7. Epub 1995/02/01. doi: 10.1016/0190-9622(95)90134-5. PubMed PMID: 7829710 . 
It is made available under a CC-BY-NC-ND 4.0 International license .

11. World Health Organization. WHO multidrug therapy (MDT) Geneva: WHO; 2013 [04/04/2020]. Available from: https://www.who.int/lep/mdt/en/.

12. Job CK, Yoder L, Jacobson RR, Hastings RC. Skin pigmentation from clofazimine therapy in leprosy patients: a reappraisal. Journal of the American Academy of Dermatology. 1990;23(2 Pt 1):236-41. Epub 1990/08/01. doi: 10.1016/01909622(90)70204-u. PubMed PMID: 2145325.

13. Jopling WH. Side-effects of antileprosy drugs in common use. Leprosy review. 1983;54(4):261-70. Epub 1983/12/01. doi: 10.5935/0305-7518.19830032. PubMed PMID: 6199637.

14. Deps PD, Nasser S, Guerra P, Simon M, Birshner Rde C, Rodrigues LC. Adverse effects from multi-drug therapy in leprosy: a Brazilian study. Leprosy review. 2007;78(3):216-22. Epub 2007/11/27. PubMed PMID: 18035772.

15. Opromolla DVA, Dalpino D, Tonello CJS, Fleury RN, Neto JBB. Resultados inicias com clofazimina no tratamento da Hanseníase. Anais Brasileiros da Sociedade Brasileira de Dermatologia. 1972;47(1).

16. White C. Iatrogenic stigma in outpatient treatment for Hansen's disease (leprosy) in Brazil. Health Educ Res. 2008;23(1):25-39. Epub 2007/01/17. doi: 10.1093/her/cyl158. PubMed PMID: 17229777.

17. Azulay RD, da Silva NC, Zeo A, Franca M, Franca CB. Personal experience with clofazimine in the treatment of leprosy. Leprosy review. 1975;46(2 Suppl):99-103. Epub 1975/06/01. doi: 10.5935/0305-7518.19750048. PubMed PMID: 1100972.

18. da Silva NC, Zeo A, Azulay RD, Portelo AB, Franca MCB, Peluso ML. Personal experience with clofazimine in the treatment of leprosy. Anais Brasileiros da Sociedade Brasileira de Dermatologia. 1972;47(1):1-6.

19. Ministério da Saúde. Guia prático sobre hanseníase. Brasília: Ministério da Saúde, Secretaria de Vigilância em Saúde, Coordenação-Geral de Desenvolvimento da Epidemiologia em Serviços, 2017.

20. Opromolla DVA. Terapêutica multidroga. Anais Brasileiros da Sociedade Brasileira de Dermatologia. 1990;65(1).

21. Swanson RV, Adamson J, Moodley C, Ngcobo B, Ammerman NC, Dorasamy A, et al. Pharmacokinetics and pharmacodynamics of clofazimine in a mouse model of tuberculosis. Antimicrobial agents and chemotherapy. 2015;59(6):3042-51. Epub 2015/03/11. doi: 10.1128/aac.00260-15. PubMed PMID: 25753644; PubMed Central PMCID: PMCPMC4432183.

22. Deps P, Guerra P, Nasser S, Simon M. Hemolytic anemia in patients receiving daily dapsone for the treatment of leprosy. Leprosy review. 2012;83(3):305-7. Epub 2013/01/30. PubMed PMID: 23356031. 
medRxiv preprint doi: https://doi.org/10.1101/2020.12.11.20247262; this version posted December 14, 2020. The copyright holder for this preprint (which was not certified by peer review) is the author/funder, who has granted medRxiv a license to display the preprint in perpetuity.

It is made available under a CC-BY-NC-ND 4.0 International license .

23. Cerqueira SRPS, Santos LSD, Morelo EF, dos Santos Junior AdCM, Sousa CAF, Goncalves RT, et al. The interference of polypharmacy and the importance of clinical pharmacy advice in the treatment of leprosy: a case-control study. Revista da Sociedade Brasileira de Medicina Tropical. 2020;53:e20200114. Epub 2020/06/04. doi: 10.1590/0037-8682-0114-2020. PubMed PMID: 32491105; PubMed Central PMCID: PMCPMC7269535. 